\title{
Does phenothiazine give a dianion on addition of two equivalents of strong base?
}

\author{
Jacques Mortier,* Thi-Huu Nguyen, David Tilly, and Anne-Sophie Castanet \\ Université du Maine and CNRS, Unité de Chimie Organique Moléculaire and Macromoléculaire \\ (UMR 6011), Faculté des Sciences, avenue Olivier Messiaen, 72085 Le Mans Cedex 9, France \\ E-mail: jacques.mortier@univ-lemans.fr
}

\section{Dedicated to Jan Epsztajn on the occasion of his 75th Anniversary}

\begin{abstract}
A careful analysis of results obtained by different authors allowed us to unravel the pathway of the metalation reaction of phenothiazine (1) by $n$-BuLi ( 2 equiv). The reaction is shown not to yield a dilithio species as believed. Electrophiles such as $\mathrm{RCONMe}_{2}\left(\mathrm{R}=\mathrm{H}, \mathrm{Ph}, 4-\mathrm{MeOC}_{6} \mathrm{H}_{4}\right)$, $\mathrm{RCO}_{2} \mathrm{H}(\mathrm{R}=\mathrm{Ph}$ and $\mathrm{Me})$ and $\mathrm{CO}_{2}$ assist a second deprotonation.
\end{abstract}

Keywords: ortho-Lithiation reaction, phenothiazine, organolithiums, mechanism

\section{Introduction}

Much is known about the structures of lithium alkyls and amides, ${ }^{1}$ but far less about how they operate, the origin of their selectivity with aromatic substrates, and the nature of the lithiated organic compounds produced prior to workup. All crystalline organolithium salts for which an X-ray structure analysis has been successfully performed so far are dimeric, tetrameric, or hexameric aggregates, the degree of aggregation depending less upon the particular alkyllithium structure than upon solvent and added complexing or chelating agents. Structural data for ortholithiated aromatics in which the $\mathrm{Li}$ atom is intramolecularly coordinated to an $\mathrm{Me}_{2} \mathrm{~N}$ or $\mathrm{MeO}$ group have been reported. ${ }^{2}$ Crystal structures of $N, N$-diisopropyl-2-lithiobenzamide-diethyl ether complex and $N, N$-diisopropyl-2-lithionaphthamide-THF complex are dimers. ${ }^{3}$ However, by NMR spectroscopy, these dianions when dissolved in $\left[\mathrm{D}_{8}\right]$ THF give at least five observable aggregates!

The fact that ortho-lithiated aromatics are found to be more or less aggregated in solution and crystals does not, of course, tell us anything about the actual reactive species and the transition state when the electrophile is added. 


\section{Results and Discussion}

In this paper, the mechanism of the metalation of phenothiazine (1) is reanalyzed (Scheme 1). It is conventionally accepted that the reaction of $\mathbf{1}$ with two equivalents of $n$-BuLi in ether affords the lithium amide 2 which undergoes a second metalation to give the dilithio species $3^{4,5}$ Addition of DMF, $N, N$-dimethylbenzamide, 4-methoxy- $N, N$-dimethylbenzamide, the lithium salts of acetic and benzoic acids, and carbon dioxide leads to the C(1)-acylation products 4a-f whereas acetyl chloride, iodomethane and ethylene oxide give the $N(10)$-substitution products 5a-c exclusively. To explain this discrepancy in the reactivity, the authors claimed that "the site of acylation is essentially dependent on the leaving group involved in the addition". 5 a
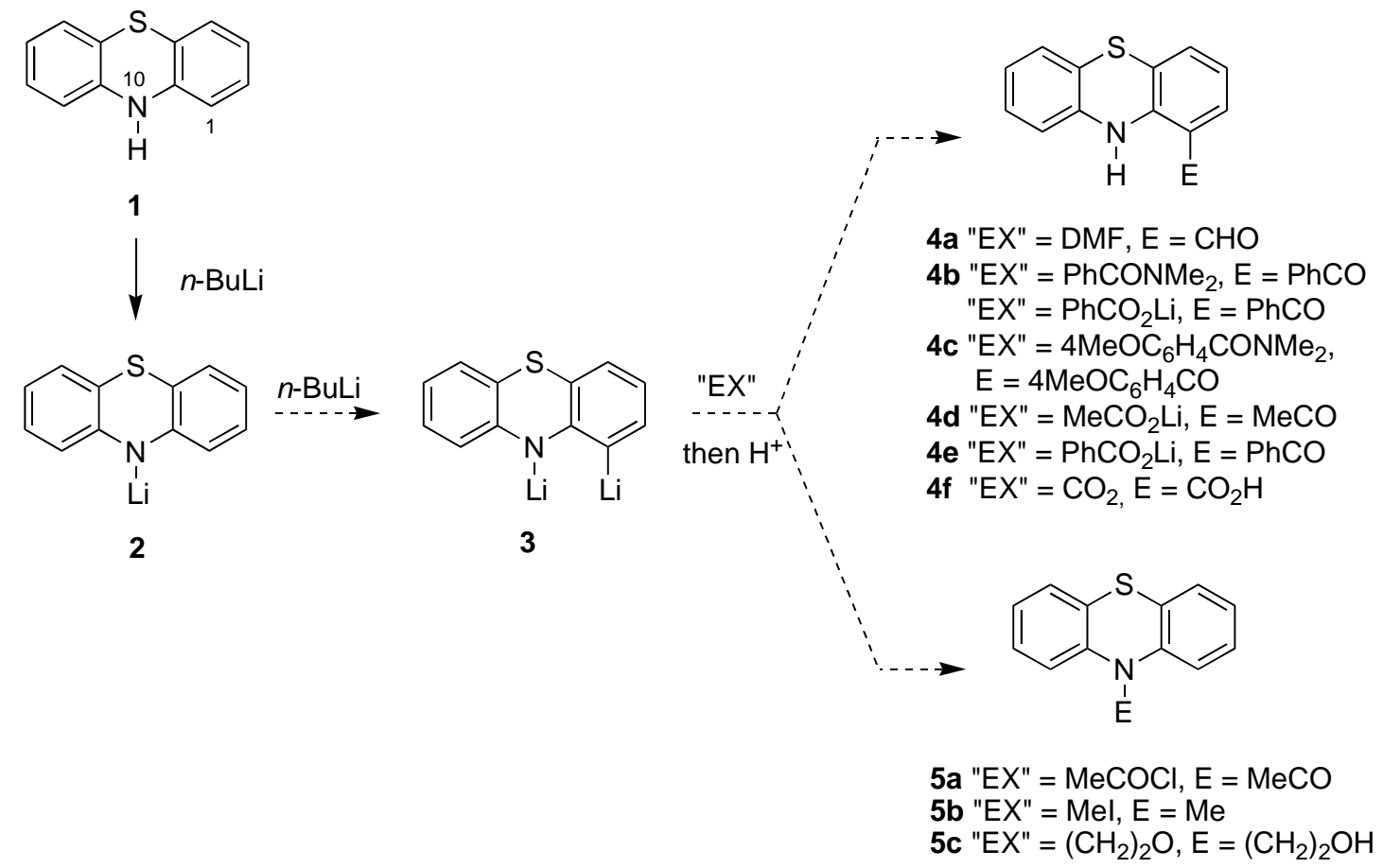

\section{Scheme 1}

This interpretation appeared to us rather inadequate and somewhat intriguing. We found initially that under the described experimental conditions, trapping with $\mathrm{D}_{2} \mathrm{O}$ led to $10 \mathrm{D}$ phenothiazine arising from exclusive substitution at the nitrogen atom $\left(100 \% 10 d_{1}\right)$. We make the following assumption, which is new and potentially valid with other substrates and electrophiles. Dianion $\mathbf{3}$ is not formed in appreciable concentration and monolithium amide $\mathbf{2}$ is the stable species present in the reaction mixture prior to addition of the electrophile. The second equivalent of $n-\mathrm{BuLi}$ remains to some extent on standby and the reaction follows different pathways depending on the nature of the electrophile.

The subsequent nucleophilic addition of monolithium amide 2 to DMF and amides (RCOX, $\mathrm{X}=\mathrm{NMe}_{2}, \quad \mathrm{R}=\mathrm{H}, \quad \mathrm{Ph}, \quad 4-\mathrm{MeOC}_{6} \mathrm{H}_{4}$ ) (Scheme 2), leading to tetrahedral lithium amino(dimethylamino)alkoxides 6a-c, must be at least as fast and most probably faster than 
quenching of $n$-BuLi by the electrophile. Ortho-metalation by $n$-BuLi directed by the lithium aminoalkoxide group ${ }^{6}$ gives a dianionic intermediate 9a-c. ${ }^{7}$ This deprotonation presumably proceeds via a prelithiation complex (PLC) 7a-c (Complex Induced Proximity Effect (CIPE) Process $)^{8}$ which immediately precedes the formation of an eight-membered ring transition state (TS) (8a-c). Internal deprotonations have been suggested to be optimal for eight-membered rings. ${ }^{9}, 10$
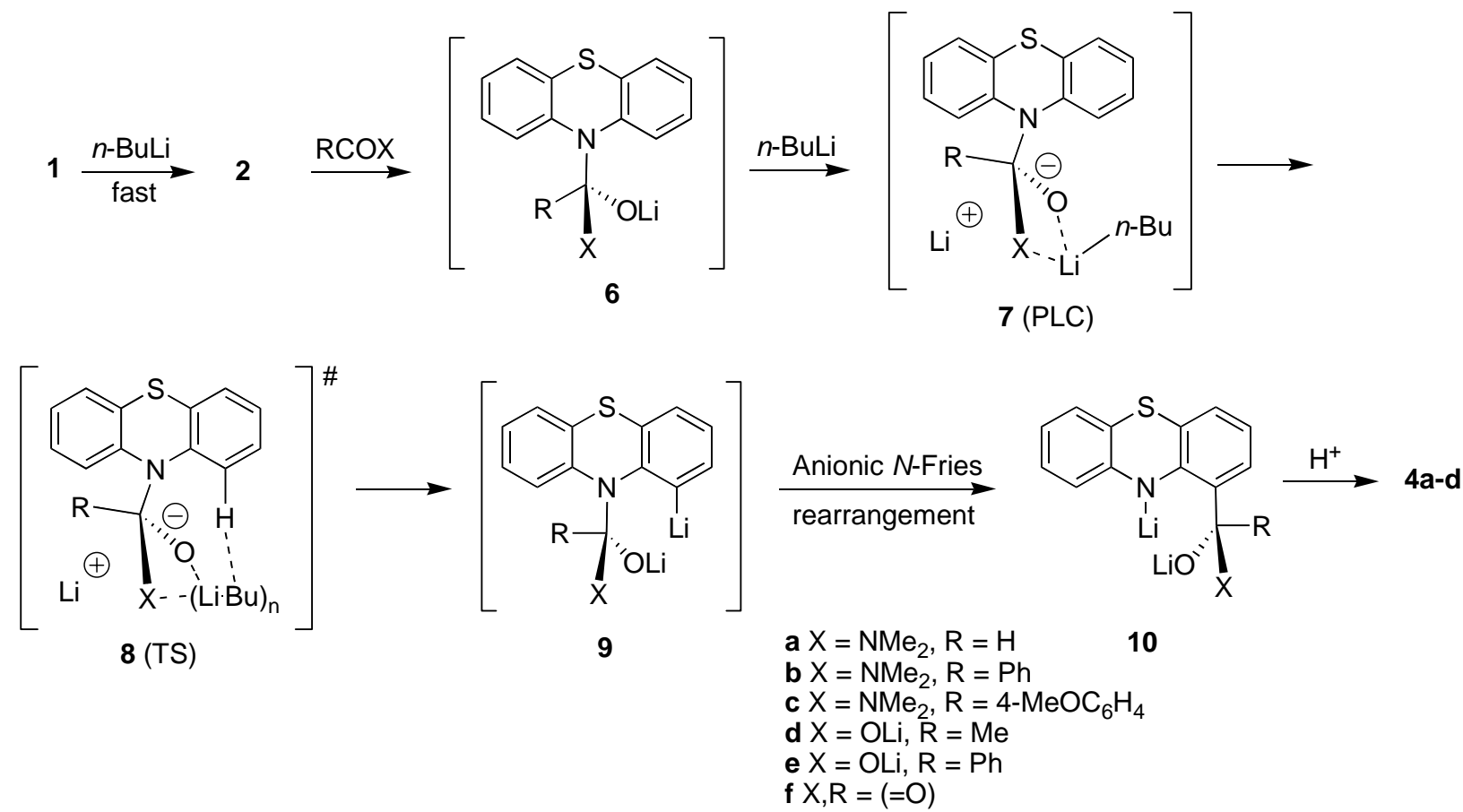

Scheme 2

The regioselectivity observed indicates that this heteroatom-directed ortho-lithiation is followed by a rapid, irreversible anionic $N$-Fries rearrangement leading to the thermodynamically more stable (less basic) lithium amide 10. Quenching of $\mathbf{1 0}$ in water gives the observed 1-acyl products 4a-c. This migration presumably involves an ion pair intermediate, wherein $\mathrm{C}-\mathrm{N}$ bond breaking precedes $\mathrm{C}-\mathrm{C}$ bond formation. ${ }^{7,11}$

Proof for the proposed mechanism is gathered by the literature (Scheme 3). ${ }^{7}$ Reaction of $N$ acylphenothiazines $5 \mathbf{g}, \mathbf{h}$ with an excess (6 equiv) of LDA or LTMP at $-78^{\circ} \mathrm{C}$ gives the $C 1$-acyl derivatives $\mathbf{4 g}, \mathbf{h}$ resulting from the anionic $N$-Fries rearrangement of the tetrahedral intermediates $\mathbf{6 g}, \mathbf{h}$ which are structurally similar to the products that arise from the reaction of monolithium amide 2 and $R C O X$ (described in Scheme 2). ${ }^{12}$ In the published work, ${ }^{7}$ intermolecular rearrangement was ruled out by a crossover experiment using equivalent amounts of $5 \mathrm{~g}$ and $5 \mathrm{~h}$; only the intramolecular rearrangement products $4 \mathrm{~g}$ and $\mathbf{4 h}$ (plus phenothiazine and 2-chlorophenothiazine), but neither of the crossover products, were obtained. The migration must be very fast since 2-chlorophenothiazines are known to readily form benzynes, even at low temperature. $^{13}$ 
When $s$-BuLi ( 6 equiv) is used as the base, the reaction of $5 \mathrm{~g}$ gives the parent phenothiazine 1 and 2-methyl-1-(pyridin-3-yl)pentan-1-one (Scheme 3). Addition of the alkyllithium to the carbonyl group of 5 gives a gem-aminoalkoxide $\mathbf{1 2}$ which is not able to direct metalation further. ${ }^{7}$ By acidic hydrolysis, the unstable $a$-amino alcohol $\mathbf{1 3}$ is cleaved to the parent phenothiazine 1 and the ketone. ${ }^{6}$ Error! Bookmark not defined. ${ }^{14}$ The methyl group of the in situ formed ${ }^{4}$ or isolated ${ }^{7} \mathrm{~N}$-acetylphenothiazine (5a) reacts with LDA or LTMP to provide a stable lithio enolate 11. 5a is retrieved after the acidic hydrolysis.
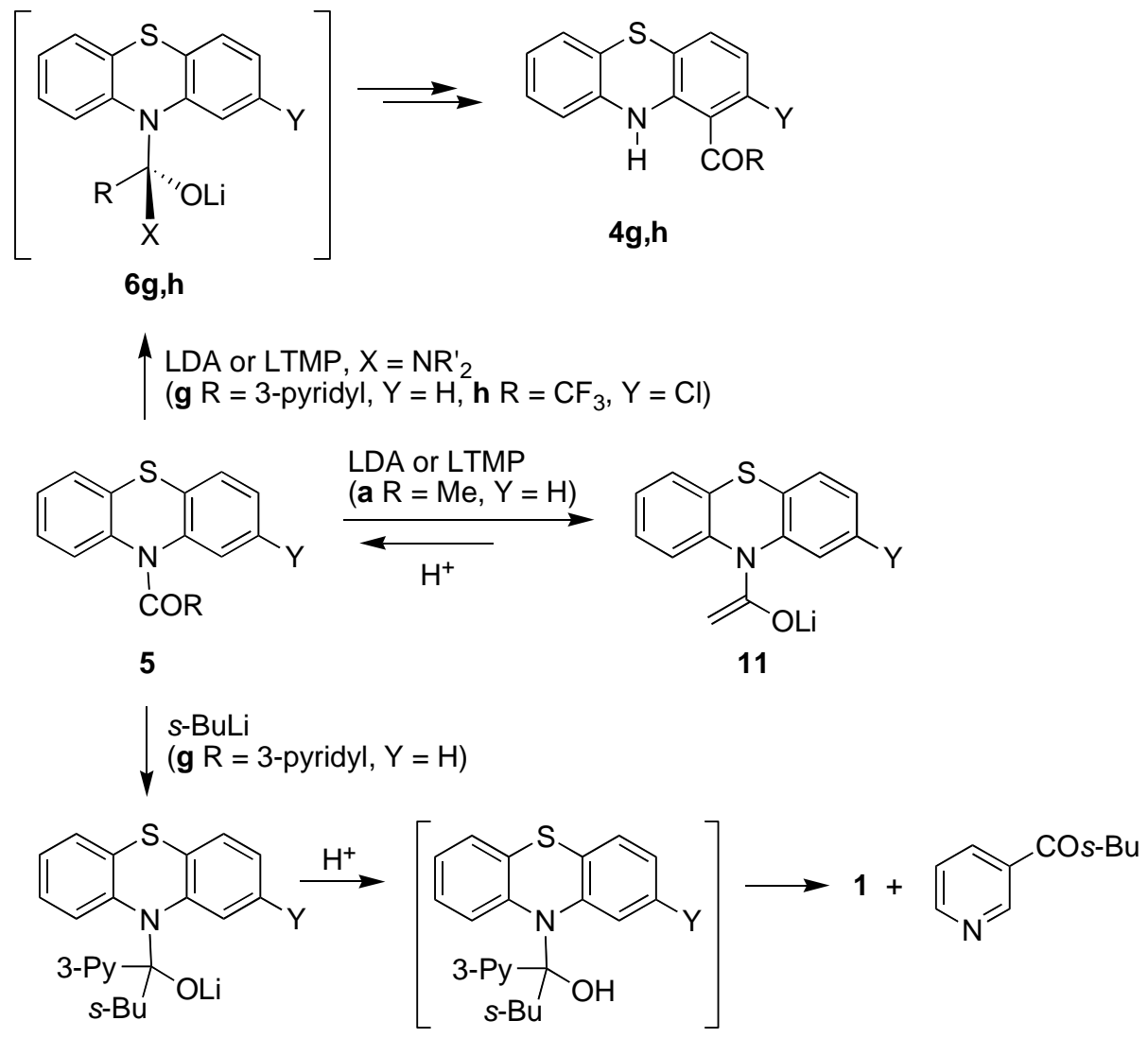

12

13

\section{Scheme 3}

The reaction of the lithium salts of acetic and benzoic acids $\left(\mathrm{RCO}_{2} \mathrm{Li}, \mathrm{R}=\mathrm{Me}, \mathrm{Ph}\right)$ under the conditions reported in Scheme 1 is believed to proceed similarly by the indicated conversion to the Fries rearrangement product 10d,e, via the prelithiation complex 7d,e (Scheme 2). The doubly charged geminal dilithio dialkoxide group $\mathrm{C}(\mathrm{OLi})_{2}$ was recently reported to direct orthometalation in the fluorenone series. ${ }^{15}$ With carbon dioxide, the reaction leads to $10 \mathrm{H}$ phenothiazine-1-carboxylic acid (4f) by $\mathrm{CO}_{2}$-migration when the mixture is allowed to warm up to room temperature. Katritzky reported convenient procedures for the regiospecific metalation of nitrogen-containing heterocycles in which an in situ formed $N$-carboxylate activates the subsequent $C$-lithiation step. ${ }^{16}$ 
In agreement with our previous comments, $N$-substitution products $\mathbf{5 b}$ and $\mathbf{5 c}$ are formed when iodomethane and ethylene oxide are the electrophiles (Scheme 1). ${ }^{17}$ Only one equivalent of $n$-BuLi is required for the metalation of $N$-methylphenothiazine 14 (Scheme 4). The sulfur atom exerts a stronger acidifying effect in its ortho position. Addition of lithium acetate followed by hydrolysis furnished the 4-acetyl derivative 15 (20\%).

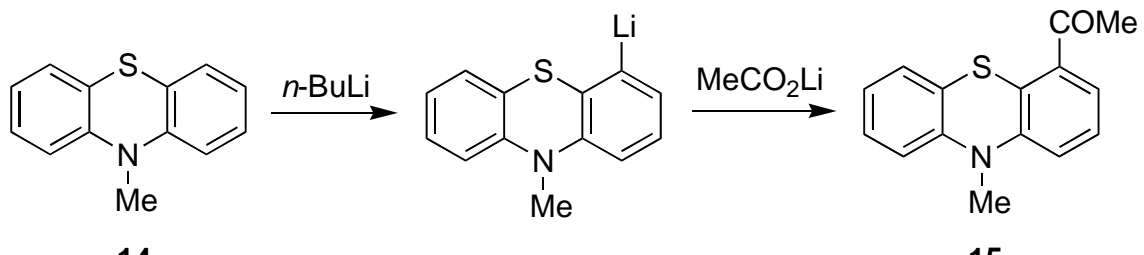

14

15

Scheme 4

o-Aminobiphenyls and derivatives ${ }^{18}$ reported by Narasimhan to undergo remote lithiation upon treatment with $n$-butyllithium in ether presumably react similarly.

Anomalies in reactivity have appeared to exist in the literature for a number of reactions of organolithiums with electrophiles. For instance, when dibenzodioxin is allowed to react with 2 molar equiv of tert-butyllithium at $-30{ }^{\circ} \mathrm{C}$ and quenched with $\mathrm{CO}_{2}$ followed by esterification, a good yield of the 1,9-diester is obtained, suggesting that a 1,9-dianion might have been generated under these conditions (Scheme 5). ${ }^{19}$ However, when the electrophile is changed to iodomethane, only 1-methyldibenzodioxin is isolated, indicating that at this temperature only monometalation occurs to any appreciable extent. It was suggested that in the special case of quenching with $\mathrm{CO}_{2}$ the initially formed 1-carboxylate salt is able to direct a subsequent deprotonation of the 9position during the quench.
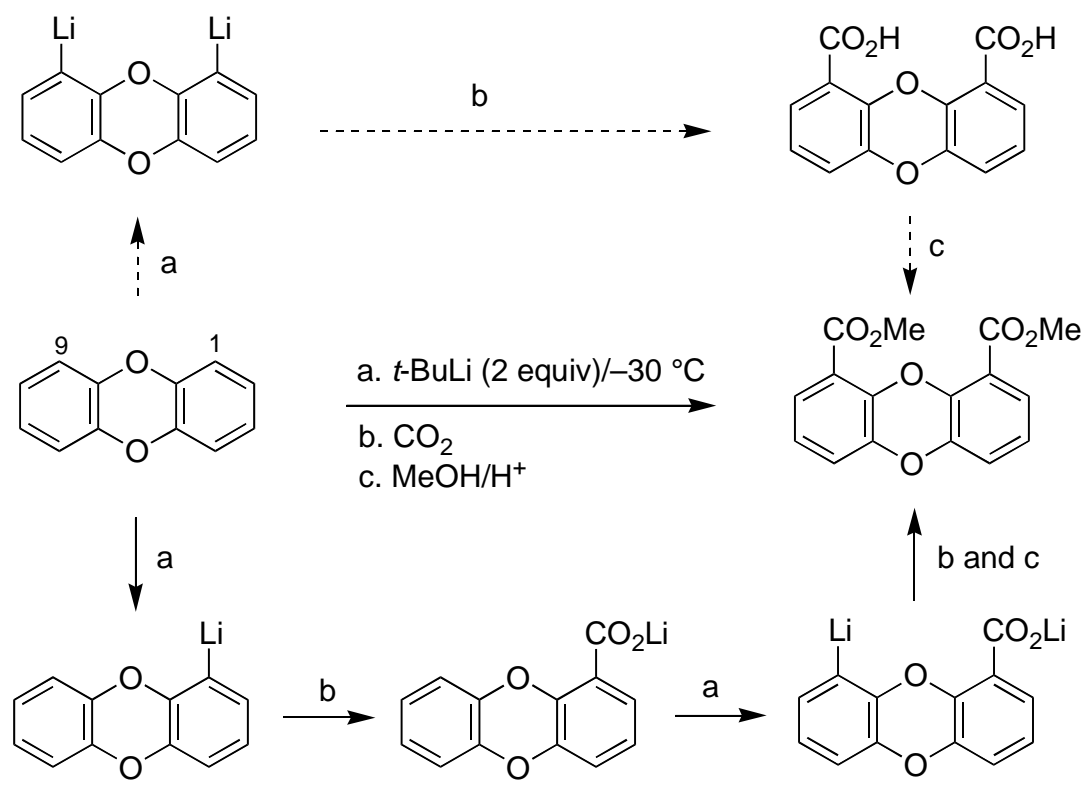

\section{Scheme 5}


We have recently shown that treatment of 4-fluorobenzoic acid using 6 equiv of LTMP at $-50{ }^{\circ} \mathrm{C}$ followed by addition of elemental iodine or dimethyldisulfide provides 4-fluoro-3(iodo/methylthio)benzoic acids, along with 4-fluoro-3,5-bis(iodo/methylthio)benzoic acids, suggesting the formation of 3-lithio and 3,5-dilithio intermediates (Scheme 6). ${ }^{20,21}$ However deuteration $\left(\mathrm{D}_{2} \mathrm{O}\right)$ and carboxylation $\left(\mathrm{CO}_{2}\right)$ result in the formation of only 3-deutero-4fluorobenzoic acid and 4-fluorobenzene-1,3-dioic acid with no detectable 3,5-bisdeutero-4fluorobenzoic acid and 2-fluorobenzene-1,3,5-tricarboxylic acid. A sequential process involving a rapid intraaggregate lithiation through a transient QUADAC (QUAsi DiAnion Complex) ${ }^{22}$ was postulated to explain the unusual reactivity of $\mathrm{Me}_{2} \mathrm{~S}_{2}$ and $\mathrm{I}_{2}$ in these transformations. ${ }^{20}$<smiles>O=C(O)c1ccc(F)cc1</smiles>

a) LTMP (6 equiv) THF, $-50^{\circ} \mathrm{C}$

b) $\mathrm{EX},-50^{\circ} \mathrm{C}$

EX/E

$\mathrm{I}_{2} / \mathrm{l}$

$\mathrm{D}_{2} \mathrm{O} / \mathrm{D}$

$\mathrm{CO}_{2} / \mathrm{CO}_{2} \mathrm{H}$<smiles>O=C(O)c1ccc(F)c(F)c1</smiles>

39
41
86
68<smiles>O=C(O)c1cc(F)c(F)c(F)c1</smiles>

47

42

0

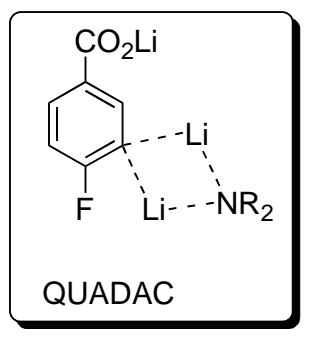

\section{Scheme 6}

The considerable current interest of both the structure and synthetic application of apparent aromatic dianion compounds demands a careful reappraisal of much of the existing data. The principle of parsimony (Ockham'razor) which underlies all scientific modelling and theory building, admonishes us to choose from a set of otherwise equivalent models of a given phenomenon the simplest one. However, «Everything should be made as simple as possible, but not one bit simpler » (Albert Einstein).

\section{Acknowledgements}

This research was supported by the CNRS, Universite du Maine and Institut universitaire de France. DT would like to thank CNRS and "Région Pays-de-la-Loire" (France) for a doctoral research grant.

\section{References and Notes}

1. Sapse, A.-M.; Schleyer, P. v. R. Lithium Chemistry, a Theoretical an Experimental Overview, Wiley: New York, 1995.

2. (a) Jastrzebski, J. T. B. H.; Van Koten, G.; Konijn, M.; Stam, C. H. J. Am. Chem. Soc. 1982, 104, 5490. (b) Butler, I. R.; Cullen, W. R.; Reglinski, J.; Rettig, S. J. J. Organomet. Chem. 
1983, 249, 183. (c) Jastrzebski, J. T. B. H.; Van Koten, G.; Goubitz, K.; Arlen, C.; Pfeffer, M. J. Organomet. Chem. 1983, 246, C79.

3. Clayden, J.; Davies, R. P.; Hendy, M. A.; Snaith, R.; Wheatley, A. E. H. Angew. Chem., Int. Ed. 2001,40, 1238.

4. Cauquil, G.; Casadevall, A.; Casadevall, E. Bull. Soc. Chim. Fr. 1960, 1049.

5. (a) Hallberg, A.; Martin, A. J. Heterocyclic Chem. 1982, 19, 433. (b) Dahlgren, T.; Hallberg, A.; Helitzer, R.; Martin, A. R. J. Heterocyclic Chem. 1983, 20, 341. (c) Hallberg, A.; AlShowaier, I.; Martin, A. J. Heterocyclic Chem. 1983, 20, 1435. (d) Hallberg, A.; AlShowaier, I.; Martin, A. J. Heterocyclic Chem. 1984, 21, 197.

6. Ortho-metalation reactions of aromatic aldehydes by $n$-BuLi in the presence of lithium dialkylamides: (a) Comins, D. L; Brown, J. D. J. Org. Chem. 1984, 48, 1937. (b) Gschwend, H. W.; Rodriguez, H. R. Org. React. 1979, 26, 1.

7. Hallberg, A.; Svensson, A.; Martin, A. Tetrahedron Lett. 1986, 27, 1959.

8. (a) Beak, P.; Meyers, A. I. Acc. Chem. Res. 1986, 19, 356. (b) Whisler, M. N.; MacNeil, S.; Snieckus, V.; Beak, P. Angew. Chem, Int. Ed. 2004, 43, 2206.

9. (a) McManus, S. P.; Capon, B. Neighboring Group Participation; Plenum Press: New York, 1976, p. 58. (b) See also: Bemardi, A.; Capelli, A. M.; Cassinari, A.; Comotti, A.; Gennari, C.; Scolastico, C. J. Org. Chem. 1992, 57, 7029. (c) Bemardi, F.; Bongini, A.; Cainelli, G.; Robb, M.; Valli, G. S. J. Org. Chem. 1993, 58, 750. (d) Romesberg, F. E.; Collum, D. B. J. Am. Chem. Soc. 1995, 117, 2166.

10. In a recent publication, we put forward for consideration that in the crucial step of the lithiation reaction, the directing and accelerating effect of the substituents might be due to the stabilization of both the initial complex and the transition structure (respectively $\mathbf{7}$ and $\mathbf{8}$ in this work). Coordination might be stronger in the transition state than in the initial complex. As a result, complexation would increase the rate of the reaction by providing a new mechanism that has a smaller activation energy $\left(E_{a}\right)$. See ref. $21 \mathrm{~d}$.

11. Metalation of 2-trifluoromethylphenothiazine with $n$-BuLi ( 2 equiv) followed by quench with hexachloroethane and dibromoethane leads to 1-chloro and 1-bromo derivatives. The presence of the $\mathrm{CF}_{3}$ could allow the formation of a dianion. See: Svensson, A.; Martin, A. Heterocycles 1985, 23, 357.

12. An analogous anionic $\mathrm{N} \rightarrow \mathrm{C}$ migration of arylsulfonamides has been reported: (a) Hellwinkel, D.; Supp, M. Angew. Chem., Int. Ed. 1970, 13, 270. (b) Hellwinkel, D.; Supp, M. Tetrahedron Lett. 1975, 1499. (c) Shafer, S. J.; Closson, W. D. J. Org. Chem. 1975, 40, 889.

13. Hallberg, A.; Dunbar, P.; Hintermeister, N. M.; Svensson, A.; Martin, A. R. J. Chem. Soc., Perkin Trans. 1 1985, 969.

14. Additionally, lithium amide 2 condenses formaldehyde to give a stable $\alpha$-aminoalkoxide. The $\mathrm{NCH}_{2} \mathrm{OLi}$ group cannot be metalated further and acid hydrolysis leads to an $\alpha$ aminoalcohol that decomposes to give $\mathbf{1}$ and formaldehyde. The implication of a diacetylated species (by reaction of $\mathbf{1 0}$ with a second molecule of RCOX) on the reaction coordinate to 
explain the formation of $\mathbf{4 a - d}$ can be ruled out since only one equivalent of amide is required to give a high yield of $4 a-d$. See ref. 5a.

15. Tilly, D.; Samanta, S. S.; De, A.; Castanet, A.-S.; Mortier, J. Org. Lett. 2005, 7, 827.

16. (a) Katritzky, A. R. ; Vazquez de Miguel, L. M. ; Rewcastle, G. W. Synthesis 1988, 215. See also: (b) Katritzky, A. R.; Akutagawa, K. Tetrahedron Lett. 1985, 26, 5935. (c) Katritzky, A. R.; Akutagawa, K. Tetrahedron 1986, 42, 2571. (d) Katritzky, A. R.; Black, M.; Fan, W.-Q. J. Org. Chem. 1991, 55, 5045.

17. $N$-Methylacetanilide and $N$-methylformanilide are rapidly deprotonated under these conditions.

18. (a) Narasimhan, N. S.; Alurhar, R. H. Indian J. Chem. 1969, 7, 1280. (b) Narasimhan, N. S.; Chandrachood, P. S. Synthesis 1979, 589. (c) Narasimhan, N. S.; Chandrachood, P. S.; Shete, N. R. Tetrahedron 1981, 37, 825.

19. Palmer, B. D.; Boyd, M.; Denny, W. A. J. Org. Chem. 1990, 55, 438.

20. Gohier, F.; Castanet, A.-S.; Mortier, J. J. Org. Chem. 2005, 70, 1501.

21. For recent work on ortho-lithiation reactions of unprotected benzoic acid derivatives, see: (a) Selectivities in reactions of organolithium reagents with unprotected 2-halobenzoic acids: Gohier, F.; Castanet, A.-S.; Mortier, J. Org. Lett. 2003, 5, 1919. (b) Ortho-lithiation of unprotected 3-bromo and 3-chlorobenzoic acids with hindered bases: Gohier, F.; Mortier, J. J. Org. Chem. 2003, 68, 2030. (c) Reactions of unprotected naphthalene-1-carboxylic acid with strong bases: Tilly, D.; Castanet, A.-S.; Mortier, J. Chem. Lett. 2005, 34, 446. (d) Mechanism of ortholithiation. Tuning of selectivities in the metalation of meta-anisic acid: Nguyen, T. H.; Chau, N. T. T.; Castanet, A.-S.; Nguyen, K. P. P.; Mortier, J. Org. Lett. 2005, 7, 2445. (e) Novel 6-substituted-2-chlorobenzoic acid syntheses: Gohier, F.; Castanet, A.-S.; Mortier, J. Synth. Commun. 2005, 35, 799. (f) Regioselective synthesis of contiguously 3- and 6-substituted 2-methoxybenzoic acid building blocks: Nguyen, T. H.; Castanet, A.-S.; Mortier, J. Org. Lett. 2006, 8, 765. (g) On the mechanism of the metalation of 2-(pyridin-3-yl)benzoic acid derivatives: Tilly, D.; Castanet, A.-S.; Mortier, J. Tetrahedron Lett. 2006, 47, 1121. (h) Regioselective metalation of unprotected 2-, 3- and 4biphenylcarboxylic acids: Tilly, D.; Samanta, S. S.; Castanet, A.-S.; De, A.; Mortier, J. Eur. J. Org. Chem. 2006, 174.

22. QUADACs have been sought in order to explain the fact that, while (supposed) dilithiation of $\mathrm{PhCH}_{2} \mathrm{CN}$ or other products by a base R'Li followed by treatment with electrophiles R'X or $\mathrm{D}_{2} \mathrm{O}$ often leads successfully to disubstituted products, the envisaged dilithium species $\mathrm{PhCLi}_{2} \mathrm{CN}$ (if it exists) has proved difficult to isolate. The existence of QUADAC structures was demonstrated by means of X-ray crystal determinations. See: (a) Boche, G. Angew. Chem., Int. Ed. Engl. 1989, 28, 277. (b) Zarges, W.; Marsch, M.; Harms, K.; Boche, G. Angew. Chem., Int. Ed. Engl. 1989, 28, 1392. (c) Ball, S. C.; Cragg-Hine, I.; Davidson, M. G.; Davies, R. P.; Edwards, A. J.; Lopez-Solera, I.; Raithby, P. R.; Snaith, R. Angew. Chem., Int. Ed. Engl. 1995, 34, 921. (d) Davies, R. P.; Raithby, P. R.; Snaith, R. Angew. Chem., Int. Ed. Engl. 1997, 36, 1215. 